\title{
Govier's Distinguishing A Priori from Inductive Arguments by Analogy: Implications for a General Theory of Ground Adequacy
}

\author{
JAMES B. FREEMAN
}

Department of Philosophy

Hunter College of The City University of New York

695 Park Avenue

New York, NY 10065

U.S.A.

jfreeman@HUNTER.CUNY.EDU

\begin{abstract}
In a priori analogies, the analogue is constructed in imagination, sharing certain properties with the primary subject. The analogue has some further property clearly consequent on those shared properties. $\mathrm{Ce}$ teris paribus the primary subject has that property also. The warrant involves non-empirical, e.g., moral intuition but is also defeasible. The argument is thus neither deductive nor inductive, but an additional type. In an inductive analogy, the analogues back the warrant from below. Distinguishing these two types of arguments by analogy gives epistemic evaluative factors primacy over resemblance factors in classifying arguments-a prescient insight on Govier's part.
\end{abstract}

Résumé: Dans les analogies a priori, le sujet analogue se construit dans l'imaginaire et partage certaines propriétés avec le sujet principal. Le sujet analogue a une autre propriété clairement en conséquence de ces propriétés partagées. Ceteris paribus le sujet principal a aussi cette propriété. La loi de passage des raisons à leur conclusion («warrant») implique l'intuition non-empirique, par exemple, l'intuition morale, mais est également révocable. L'argument par analogie n'est donc ni déductif ni inductif, mais un autre type d'argument. Dans une analogie inductive, les sujets analogues appuient la loi de passage de cidessous. Si on distingue ces deux types d'arguments par analogie, on donne primauté des facteurs d'évaluation épistémiques sur les facteurs de ressemblance dans la classification des arguments - une idée visionnaire de la part de Govier.

Keywords: a posteriori warrants, a priori analogy, ceteris paribus, inductive analogy, warrant

(C) James B. Freeman. Informal Logic, Vol. 33, No. 2 (2013), pp. 175-194. 


\section{James B. Freeman}

In her text, A Practical Study of Argument, ${ }^{1}$ Trudy Govier distinguishes a priori from inductive arguments by analogy. In an a priori analogy, one constructs an analogue in imagination having certain properties. The primary subject, with which the analogue is compared, also has these properties and they constitute the similarities between primary subject and analogue argued from. The point is that this analogue need not be actual and typically it will be imaginary. The analogue has some further property, the similarity argued for. Hence, by analogy, i.e., by virtue of the relevant similarities argued from, one concludes, ceteris paribus that the primary subject has this further property also. The expectation is that the analogue's having this further property is clear and that it is clear that the analogue has it because of having the properties it shares with the primary subject. Considered by itself, whether the primary subject has the similarity argued for is unclear. By virtue of the comparison and the need to treat like cases like, one can then "see" that the primary subject has this further similarity with the analogue.

One might want to say that the analogy is a priori because the analogue is constructed in imagination, not empirically observed. Govier endorses this explanation when she says "Because the analogue in this kind of consistency reasoning need not be something that actually happened, the analogy used may be called an a priori analogy" (Govier 2010, p. 328). Again, "In an a priori analogy, the analogue need not be a real case. It can be entirely hypothetical and may, in fact, be positively fanciful" (Govier 1999, p. 138). "The analogy will be a good one insofar as the analogue and the primary case share all the features which are logically relevant to the conclusion. Whether this is the case is something we can determine a priori, from reflective examination of the cases" (Govier 2010, p. 328).

By contrast with Govier, I believe that a proper understanding of why these arguments are properly classed as a priori analo-

1 This text is now in its Seventh Edition (2010). All quotes from this text are from this edition.

(C) James B. Freeman. Informal Logic, Vol. 33, No. 2 (2013), pp. 175-194. 
gies depends on factors other than the possibly hypothetical status of the analogue. The Toulmin model can bring this issue into proper focus. Govier has presented a model of a priori analogies. Where ' $A$ ' indicates the analogue, ' $B$ ' the primary subject, ' $x, y, z$ ' the similarities argued from and ' $\mathrm{W}$ ' the similarity argued for, the schema
A has $\mathrm{x}, \mathrm{y}, \mathrm{z}$
$\mathrm{B}$ has $\mathrm{x}, \mathrm{y}, \mathrm{z}$
$\mathrm{A}$ is $\mathrm{W}$.
Therefore, $\mathrm{B}$ is $\mathrm{W}$

(Govier 1999, p. 140) constitutes the basic schema for a priori analogies. I believe it would be more perspicuous to reverse the order of the second and third premises, and to explicitly add the "ceteris paribus" qualifier.
A has $\mathrm{x}, \mathrm{y}, \mathrm{z}$
$\mathrm{A}$ is $\mathrm{W}$.
$\mathrm{B}$ has $\mathrm{x}, \mathrm{y}, \mathrm{z}$
Therefore, ceteris paribus, $\mathrm{B}$ is $\mathrm{W}$.

Why do these changes give us a better focus on a priori analogies? First, arguments by analogy are defeasible. Consider this reconstruction of Govier's first example of an a priori analogy (Govier 1999, p. 141):

1. Eating half-chewed food from someone else's plate or drinking water that had previously held someone's teeth involves ingesting substances exposed to someone else's bodily interior.

2. No one should be forced to eat half-chewed food from someone else's plate or drink water that had previously held someone's teeth.

3. Inhaling smoke which has been in the recesses of a smoker's lungs is ingesting a substance exposed to someone else's bodily interior.

(C) James B. Freeman. Informal Logic, Vol. 33, No. 2 (2013), pp. 175-194. 


\section{James B. Freeman}

Therefore, ceteris paribus,

4. No one should be forced to inhale such second-had smoke.

We can easily see that this argument is defeasible. Although it might tax our imaginations, it is certainly not logically impossible that there be some reason for forcing people to breathe secondhand smoke, which could be offered as a rebutting defeater to the argument. We shall later see how this argument may supplement those Govier gives against reconstructing a priori analogies as deductive arguments.

Why does switching the order of the second and third premises in Govier's model give a better focus on a priori analogies and what does Toulmin's model have to do with it? Our claim is that B is $\mathrm{W}$. Our data are that $\mathrm{B}$ has $\mathrm{x}, \mathrm{y}, \mathrm{z}$. How then do the first two premises in the model function? On our view, they function to make perspicuous the warrant which sanctions the inferential step from $\mathrm{x}, \mathrm{y}, \mathrm{z}$ to $\mathrm{W}$. As we see it, the function of the first two premises is not necessarily to back the warrant (give evidence for its associated qualified universal generalization) but to aid the recipient of this argument in seeing the inferential connection between being $\mathrm{x}$, $\mathrm{y}, \mathrm{z}$ and being $\mathrm{W}$. How then is this warrant cognized? We shall argue that the cognizing is a matter of a priori intuition, more specifically moral intuition. Diagramming the argument according to the Toulmin model, we have Figure 1 (see next page):

Do we need to resort to an empirical survey to justify the claim that if an action involves ingesting something which has been within someone else's body, it is wrong to force someone to perform that action? What is needed is empathetic entering into a situation where such an action is forced to see the connection between performing such an action and the wrongness of forcing its performance. The latter supervenes upon the former and we see this general (though defeasible) connection through moral intuition, not through empirical inquiry. So the hallmark of the class of a priori analogies is having warrants authorizing the step from the similarities argued from to the similarity argued for which are apprehended a priori. The hallmark concerns the epistemic status of the warrant,

(C) James B. Freeman. Informal Logic, Vol. 33, No. 2 (2013), pp. 175-194. 
not whether we may reflectively compare analogue and primary subject for similarities argued from.

\author{
Inhaling smoke \\ which has been \\ in the recesses \\ of someone's \\ lungs is ingest- \\ ing a substance \\ which has been \\ within someone \\ else's body

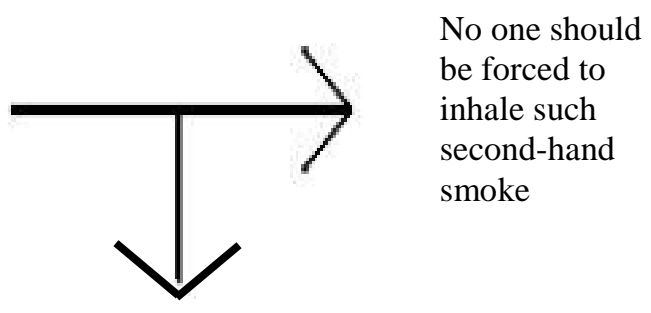 \\ On account of \\ From: Action $\mathrm{X}$ involves ingesting \\ a substance which has been \\ within someone else's body \\ To infer ceteris paribus: No one should \\ be forced to perform action $\mathrm{X}$
}

\title{
Figure 1
}

One may ask how these a priori warrants are backed. If it is self-evident that from an act's involving ingesting something which has been in someone else's body we may infer (ceteris paribus) that the act is one that no person can be compelled to perform, then the warrant is self-backed. It needs no further backing. This is not to say that all warrants used in arguments by a priori analogy need be self-evident or be self-backed. The point is that many of these warrants are self-evident, and this gives a further reason for regarding them as a priori.

Moral arguments where one infers a conclusion about an act's having a certain deontic property on the basis of its having certain non-deontic but deontically relevant properties are paradigm cases of arguments with synthetic a priori warrants.

From: $\mathrm{X}$ promised to do $\mathrm{Y}$

To infer ceteris paribus: $\mathrm{X}$ ought to or has a duty to perform $\mathrm{Y}$ 
Our moral intuition lets us grasp that we may go from the deontically relevant property of making a promise to the deontic property of having a duty to keep that promise. This is basically the insight of W. D. Ross in (1930). For Ross, principles of prima facie duty are synthetic a priori. On his account, we learn to recognize such principles in a way analogous to our learning elementary arithmetic truths. We see instances of two things and two things put together to make four. We grasp the general arithmetical principle not by inductive generalization but from these illustrations. Likewise, from examples of promise making we sense that the person making the promise is bound (ceteris paribus) to keep it. From these examples, we intuit the general connection between promise making and having a duty to keep those promises. ${ }^{2}$

Ross proposes that our moral intuition grasps synthetic a priori connections between deontically relevant properties and prima facie duties, what may be duties outright absent conflicts of duties. Following Rawls (1971, pp. 341-42), we regard our principles as carrying us to the duties themselves, but in a defeasible, not certain step. We speculate that Ross was unwilling to allow a priori principles to be defeasible. He regarded the step from deontically relevant properties to prima facie duties as certain, and then the step from a set of possibly conflicting prima facie duties to an overriding duty as a matter of intuitively weighing prima facie duties against each other. We are allowing principles to be both a priori and defeasible. In this way, we avoid postulating a realm of prima facie duties in our moral ontology by taking what for some may be the audacious step of allowing a priori truths which are not certain. But if the warrants identified in arguments by a priori analogy are indeed a priori and synthetic, and if the arguments of which they are warrants are defeasible, we claim we have made our case.

Why then are these a priori warrants (or their associated general conditionals) not analytic, as the semantically necessary "All

\footnotetext{
2 For a further elaboration of our views on moral epistemology, see our (2005, Chapter 9).
}

(C) James B. Freeman. Informal Logic, Vol. 33, No. 2 (2013), pp. 175-194. 
bachelors are unmarried" is analytic? Consider. Making a promise is to perform a certain act. We may describe the performance of that action. But to see that performance of the communicative act binds one in some way to perform some further act, we must see a connection between the communicative act and being morally bound in a certain way. The concept of this connection is something additional to the concept of having made a promise and is not contained in the latter as " being unmarried" is contained in the concept of "bachelor." To see why just look at the associated generalization again. To be true, it must be qualified with "ceteris paribus." The unqualified general universal is subject to counterexample. Recalling the example from Plato's Republic, if someone promises to return a weapon to its owner at a time when the owner is obviously mentally deranged, is that person absolutely obligated to return it?

Harrison in (1967, pp. 71-72) gives a further argument which we see decisive against the view that such deontic generalizations are analytic. The view makes such generalizations "trivial and useless" (Harrison 1967, p. 72). If to make a promise means to incur some obligation, then one cannot agree that one has made a promise unless one has also agreed that the act involves morally binding oneself. Otherwise, the act was not a promise. But this is not right. The generalization links the act as described with a morally evaluative concept not a component of the description of the act. Harrison brings this out forcefully with this example: To say that fornication is wrong is to judge acts describable in a certain way. But then one must argue that there are exceptions and such an argument is not logically absurd. It is not absurd to argue that the generalization needs to be qualified by a "ceteris paribus" clause. But if being wrong is part of the very meaning of 'fornication,' as being unmarried is part of the very meaning of being a bachelor, then such an argument is absurd. On the analytic view, if the acts were not wrong, they would not be instances of fornication to begin with. The analytic proposition is logically unassailable but trivial. The deontic judgment is neither. This shows they are instances of two different types of judgments.

(C) James B. Freeman. Informal Logic, Vol. 33, No. 2 (2013), pp. 175-194. 


\section{James B. Freeman}

That arguments by a priori analogy are defeasible constitutes a decisive objection to all attempts to show them to be deductive arguments. This is a point Govier is anxious to establish in (1999). She argues that the model of arguments by a priori analogy apparently presupposes "It is in virtue of $\mathrm{x}, \mathrm{y}, \mathrm{z}$ that $\mathrm{A}$ is W." She then continues that "it is a very short step to a universal statement ... "All things which are $\mathrm{x}, \mathrm{y}, \mathrm{z}$ are W'" (1999, p. 142). We agree that the former statement is presupposed. But how is it presupposed? The warrant authorizing the step from " $\mathrm{A}$ is $\mathrm{x}, \mathrm{y}, \mathrm{z}$ " to " $\mathrm{A}$ is $\mathrm{W}$ " presupposes the statement as an assertion about conceptual connection. But that warrant, as we have pointed out, is defeasible. Hence, although the step from

It is in virtue of $\mathrm{x}, \mathrm{y}, \mathrm{z}$ that $\mathrm{A}$ is $\mathrm{W}$.

to

All things which have $\mathrm{x}, \mathrm{y}, \mathrm{z}$ are $\mathrm{W}$.

may seem short and innocent, it is really a big step and guilty of misunderstanding what "in virtue of" means in this context. True, that $\mathrm{A}$ has $\mathrm{x}, \mathrm{y}, \mathrm{z}$ is the reason why $\mathrm{A}$ is $\mathrm{W}$, but the general connection holds typically, not universally.

Govier points out that the error is compounded further. "It is in virtue of $\mathrm{x}, \mathrm{y}, \mathrm{z}$ that $\mathrm{A}$ is $\mathrm{W}$ " is taken not as the warrant, but as an unstated premise, from which "all things which have $\mathrm{x}, \mathrm{y}, \mathrm{z}$ are W" is taken as a better formulation, to be added to state the unexpressed premise. But then the a priori analogy is converted into a deductively valid argument. As Govier points out, the generalization renders the two premises in the argument referring to A logically redundant. Further, the unqualified universal may very well not be acceptable. This point should be stressed. A qualified generalization may be quite plausible, while an unrestricted universal generalization might be questionable or, worse, false and easily counterexampled. Notice that on our reconstruction of the argument on the Toulmin model, although the premises concerning A are not included in the data, they are epistemically necessary to highlight the warrant. As Govier points out, an argument may make

(c) James B. Freeman. Informal Logic, Vol. 33, No. 2 (2013), pp. 175-194. 
an assumption, but 'this 'assumption' can play various roles. It might be a background assumption or it might be an unstated premise" $(1999$, p. 146). It is precisely our point that the assumption is a background assumption, to wit a warrant.

If our case that a priori analogies presuppose defeasible synthetic a priori warrants is cogent, Govier's point is established. These a priori analogies are defeasible and hence not deductive arguments. But their warrants are a priori, not inductively backed. Hence they are not inductive arguments. They constitute or are included in a further type of argument. We hold that this point has further implications for the general question of determining whether the premises of an argument constitute adequate grounds for its conclusion. But before proceeding to discuss this point, we need to consider inductive analogies.

The analogue or analogues in an inductive analogy are observed, showing that they share certain properties with the primary subject. That the analogues satisfy some further property is again a matter of observation. But on the basis of the former points of similarity, the argument concludes that the primary subject has this further property, the similarity argued for. Like a priori analogies, inductive analogies presuppose

It is in virtue of $a_{1}, \ldots, a_{n}$ satisfying $P_{1}, \ldots, P_{m}$ that $a_{1}, \ldots, a_{n}$ satisfy Q

where $\mathrm{P}_{1}, \ldots, \mathrm{P}_{\mathrm{m}}$ are the similarities argued from and $\mathrm{Q}$ the similarity argued for. Again, since inductive analogies are defeasible arguments, it is wrong to construe this presupposition as an unqualified universal generalization which, if taken as a premise, would convert the inductive analogy into a deductive argument. Rather, the inductive analogy presupposes a defeasible warrant:

From: $\quad x$ has $\mathrm{P}_{1}, \ldots, \mathrm{P}_{\mathrm{m}}$

To infer ceteris paribus: $x$ has $\mathrm{Q}$

(C) James B. Freeman. Informal Logic, Vol. 33, No. 2 (2013), pp. 175-194. 


\section{James B. Freeman}

We construe the information about $\mathrm{a}_{1}, \ldots, \mathrm{a}_{\mathrm{n}}$ as empirical backing for the warrant.

Recall that in an argument by analogy, whether a priori or inductive, we are trying to establish that the primary subject satisfies some property, the similarity argued for. We are given a premise that the primary subject satisfies one or more similarities argued from. We get from that premise to the conclusion by noting that one or more analogues satisfying the similarity argued from also satisfy the similarity argued for. The point of this assertion is to indicate a general connection between the similarities argued from and the similarity argued for. In an a priori analogy, the analogue illustrates this general connection, which is synthetic a priori. In an inductive analogy, the general connection between similarities argued for and similarity argued from is empirical. The analogues back the warrant inductively "from below," giving these instances to justify reasoning according to the warrant.

This analysis motivates some popular textbook instructions for comparing the strength of arguments by analogy, properly applied just to inductive analogies. In his classic text, Copi presents various comparative principles. Using our terminology, one principle indicates that the greater the number of analogues, the stronger the argument. This makes perfect sense for an inductive analogy. If we consider the universal generalization corresponding to the warrant, the premises asserting that the analogues satisfy both the similarities argued from and the similarity argued for may also serve as the premises in an inductive generalization argument. Ceteris paribus, the larger the sample, the stronger the argument. Another comparative principle asserts that the more dissimilarities among the analogues, the stronger the argument. Dissimilarities among the analogues constitute counters to rebuttals that raise the question of whether some condition other than the similarities argued from is the reason why the analogues satisfy the similarity argued for. The more diverse the analogues among themselves, the more likely ceteris paribus that the reason why they all satisfy the similarity argued for is their satisfying the similarities argued from and not some further unrecognized variable. Again, this is a feature of an

(C) James B. Freeman. Informal Logic, Vol. 33, No. 2 (2013), pp. 175-194. 
argument trying to establish an empirical connection between the similarities argued from and the similarity argued for. If the connection is a priori, we see the connection intuitively by being presented with one (or more) analogies as illustrative examples.

Note that we are not arguing that arguments by inductive analogy can be parsed into two subarguments, an inductive enumeration argument to the unstated conclusion that all things satisfying the similarities argued from also satisfy the similarity argued for (without qualification, not hedged with "ceteris paribus") followed by a deductive quasi-syllogism from that generalization linked with the premise asserting that the primary subject satisfies the similarities argued from to the conclusion that the primary subject satisfies the similarity argued for. Rather, we are suggesting that the premises which assert that the analogues satisfy both the similarities argued from and the similarity argued for are backing. The warrant licences the inference to the primary subject's satisfying the similarity argued for from the premise that it satisfies the similarities argued from. The difference between a priori and inductive analogies is that the warrant expresses an empirical, rather than a priori connection. Given the Toulmin model, we may diagram such arguments in the following way, where ' $\mathrm{a}_{1}, \ldots, \mathrm{a}_{\mathrm{n}}$ ' indicate the analogues, ' $b$ ' the primary subject, ' $\mathrm{P}_{1}, \ldots, \mathrm{P}_{\mathrm{m}}$ ' the similarities argued from, and Q' the similarity argued for (see Figure 2 on the next page) $:^{3}$

This parsing of inductive analogies resembles closely Mill's analysis of quasi-syllogisms, i.e. arguments of the form
All $\mathrm{F}$ are $\mathrm{G}$.
$\mathrm{a}$ is $\mathrm{F}$.
Therefore $\mathrm{a}$ is $\mathrm{G}$

\footnotetext{
3 Our placing of 'ceteris paribus' interrupting the line from data to claim instead of immediately before the claim (Toulmin's positioning) instances our position that the modal qualifier modifies the connection between data and claim, not the claim itself. See our argument in (2011, pp. 17-19).
}

(C) James B. Freeman. Informal Logic, Vol. 33, No. 2 (2013), pp. 175-194. 
186 James B. Freeman

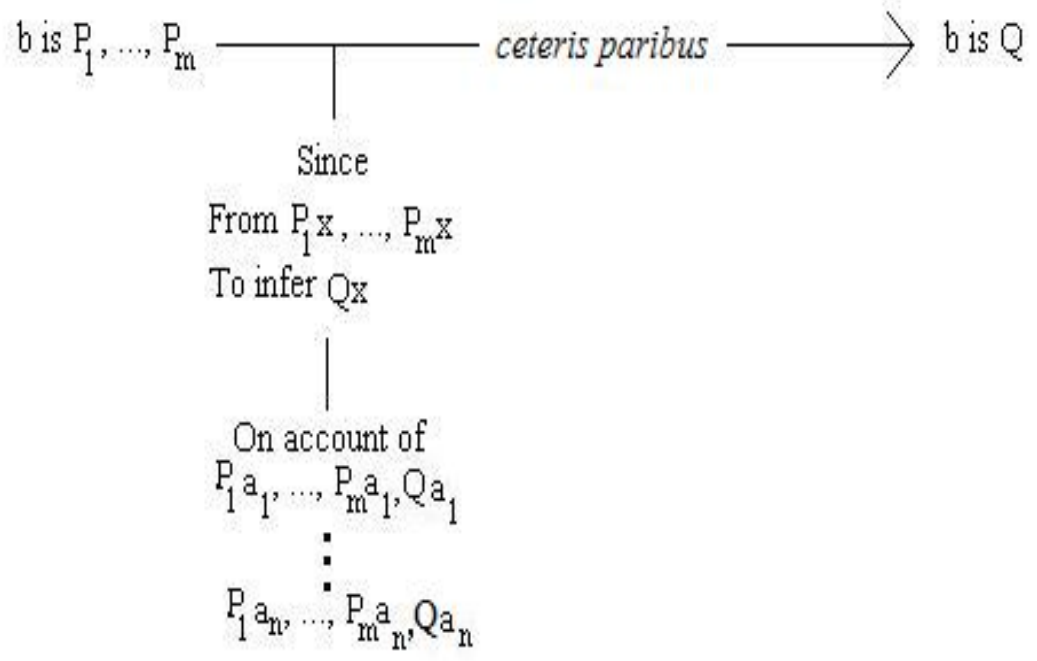

Figure 2

in Book II, Chapters ii-iv of his (1973/1843). For Mill, inference is always from particulars to particulars. Having observed a number of particulars (analogues) which exhibit co-variation of $F$ with $G$, we may record in a memorandum that we may infer $\mathrm{x}$ is $\mathrm{G}$ from $\mathrm{x}$ is F. In a quasi-syllogism, we are really inferring the conclusion directly from the premises of an inductive enumeration argument supporting the apparent universal premise. The argument really is

$a_{1}$ is an $F \& a_{1}$ is a $G$

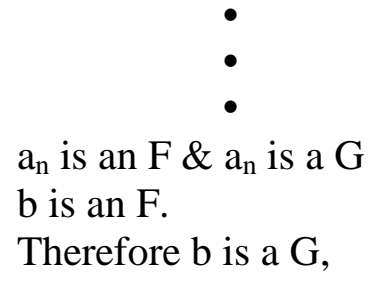

i.e., we have an argument by inductive analogy. Although we could construe the reasoning in this argument according to the pattern:

(C) James B. Freeman. Informal Logic, Vol. 33, No. 2 (2013), pp. 175-194. 
$a_{1}$ is an $F \& a_{1}$ is $a$

$a_{n}$ is an $F \& a_{n}$ is a $G$

Therefore All F's are G's

$\mathrm{b}$ is an $\mathrm{F}$.

Therefore $b$ is a $\mathrm{G}$,

we need not include the move to an intermediate conclusion as an intermediate step. From childhood we reason from particulars to particulars, reasoning or inferring long before we could formulate a general proposition. This holds true of adults also. For Mill, general propositions are merely registers of such inferences already made, and short formulae for making more (1973/1843, p. 193). The conclusion of a syllogism is not an inference drawn from the formula, but an inference drawn according to the formula, i.e. at least in the context of a quasi-syllogism, the general proposition is a warrant and the information about co-variation furnishes the backing, as our construal according to the Toulmin model manifests. $^{4}$

Having contrasted a priori and inductive analogies on the epistemic difference of how their warrants are backed, we are ready to both appreciate and critically revise the moral Govier draws from recognizing a class of a priori analogies: Arguments by analogy constitute a distinct type of argument, neither deductive nor inductive. Those analogical arguments that are neither deductive nor inductive are rather a priori analogies. By contrast, inductive analogies are properly construed as inductive arguments. But if a priori analogies are defeasible, yet the warrant linking premise and conclusion not backed by inductive enumeration or some other form of recognized inductive argument, a priori analogies are neither deductive nor inductive.

\footnotetext{
${ }^{4}$ For our discussion and critical appraisal of Mill on the syllogism, see our (2011, pp. 76-80).

(c) James B. Freeman. Informal Logic, Vol. 33, No. 2 (2013), pp. 175-194.
} 
This moral has an important corollary. We make the deductive/inductive distinction because different standards and different procedures are appropriate in judging connection adequacy for these two types of arguments. We do not judge the adequacy of inductive enumeration arguments through Venn diagrams nor do we ask about the representativeness of a sample in judging whether a categorical syllogism is valid or invalid. The inductive/deductive typology basically concerns the criteria and methods of assessing connection adequacy. Resemblances between arguments, including structural resemblances, are secondary. By splitting arguments by analogy into two classes, we are holding that the structural similarities between the two classes are outweighed by properly identifying the factors on which their connection adequacy depends.

Our claim that a priori analogies are defeasible a priori arguments will be strengthened if we can show that there are other defeasible a priori arguments, that the classification is not ad hoc. We may easily identify such arguments. Certainly conductive arguments from premises asserting that some property relevant to either intrinsic, deontic, or aretaic value to a conclusion claiming that some instance of intrinsic, deontic, or aretaic value holds are defeasible a priori, where the premises establish a prima facie case for the conclusion. For example,

You promised to return those weapons to Jones when he asked for them, which he has just done. So you should return Jones' weapons to him.

This argument can be parsed in two ways, according to Ross (1930, pp. 33, 41) or according to Rawls (1971, pp. 34-42). For Ross it is certain or self-evident that you have a prima facie obligation to return the weapons. Inferring an overall obligation from recognized prima facie obligations is a further, and defeasible, inferential step. By contrast, for Rawls By contrast, for Rawls we infer an obligation outright but the inference is defeasible. If Jones is clearly deranged when asking for his weapons back, raising distinct questions about whether he will harm himself or others, the obligation

(C) James B. Freeman. Informal Logic, Vol. 33, No. 2 (2013), pp. 175-194. 
in virtue of making a promise is defeated, at least until Jones recovers. Such conductive arguments, a prime concern of Wellman in (1971), are defeasible a priori.

We may reinforce this point by considering two further examples which Wellman gives to motivate his claim that conductive arguments constitute a third type of argument beyond deductive and inductive.

This is a good book because it is interesting and thought provoking.

Although he is tactless and nonconformist, he is still a morally good man because of his underlying kindness and real integrity. (Wellman 1971, p. 51)

What is the connection between a book's being interesting and its being good (reading the book being an intrinsically good state of affairs)? Do we learn that being interesting is a good making property through an empirical survey, reading a lot of interesting books and finding each good, or do we recognize that being interesting is a good making property after encountering a few illustrations, the way a child may recognize that $2+2=4$ after seeing a few examples? Is being good analytically contained in being interesting? How so? Reflection should indicate that the connection is synthetic a priori It is also defeasible. A pornographic novel may be interesting, but without some redeeming social value it is certainly not good. We may repeat this argument for Wellman's third example, mutatis mutandis. What is the connection between having the trait of underlying kindness or of real integrity and being morally good? Is this an empirical, inductive connection or one we may recognize immediately upon acquaintance with kindness or integrity? Again, is the connection merely analytic? Again, someone might be kind but might also have serious character flaws (he finds nothing wrong with sealing from others to get the wherewithal for his acts of kindness). The connection is defeasible. We are not here claiming that all conductive arguments are defeasible $a$ priori. The point is that a number of conductive arguments are. Hence, a priori anal-

(C) James B. Freeman. Informal Logic, Vol. 33, No. 2 (2013), pp. 175-194. 


\section{James B. Freeman}

ogies are not the sole members of the class of defeasible a priori arguments.

Right at the beginning of his chapter on conductive arguments, Wellman allows that there are further types of arguments neither deductive nor inductive. He mentions arguments by analogy, if they "cannot be reduced to some sort of statistical inference" (1971, p. 52). Further

At some point statistical or probability inference will require a kind of reasoning that is neither deductive nor inductive. I also believe that there is something that might be called explanatory reasoning: reasoning from a body of data to a hypothesis that will render them intelligible. $(1971$, p. 52)

The case of explanation is especially intriguing in connection with the class of defeasible $a$ priori arguments. Consider the prime principle of confirmation:

Whenever we are considering two competing hypotheses, an observation counts as evidence in favor of the hypothesis under which the observation has the highest probability. (Collins 1999; reprinted in Pojman and Rea 2012, p. 204)

We may express the principle more formally as the Likelihood Principle:

(LP) Observation $\mathrm{O}$ supports hypothesis $\mathrm{H} 1$ more than it supports hypothesis $\mathrm{H} 2$ if and only if $\operatorname{Pr}(\mathrm{O} / \mathrm{H} 1)>$ $\operatorname{Pr}(\mathrm{O} / \mathrm{H} 2)$. (Sober 2004, p. 100)

As Sober points out, the acceptability of the Likelihood Principle is open to debate, but the principle appears distinctly plausible. Collins points out that "Many philosophers think that this principle can be derived from the probability calculus" (Collins 2012, p. 205, italics in original). We cannot go into the acceptability issue here. Let us suppose it true that this principle can be derived ultimately 
from the axioms of probability theory. Then the epistemic status of the principle becomes that of the probability axioms.

Set theory is commonly recognized as a foundation for much of mathematics. Thus, we shall expect that the axioms of the probability calculus can be derived as theorems from the axioms of set theory. Hence the epistemic status of probability theory becomes the epistemic status of set theory. Quine (1970) has given a telling argument that set theory is not logic and that set-theoretical truths are not logical truths. "As soon as we admit ' $\in$ ' as a genuine predicate, and classes as values of quantifiable variables, we are embarked on a substantive mathematical theory" (Quine 1970, p. 72). Mathematical truths are not logical truths. Hence, pace Quine's rejection of the analytic/synthetic dichotomy, they are not analytic and so neither are the axioms or theorems of probability theory. But they are not a posteriori either.

Now clearly, we may see the prime principle of confirmation backing the following warrant:

From: $\mathrm{O} \& \operatorname{Pr}(\mathrm{O} / \mathrm{H} 1)>\operatorname{Pr}(\mathrm{O} / \mathrm{H} 2)$

To infer ceteris paribus: $\mathrm{H} 1$

Consider the following instance:

The defendant's fingerprints are all over the gun and semen containing his DNA has been found on the body of the victim. The probability of this evidence on the hypothesis that the defendant raped and murdered the victim is greater than on the hypothesis that some unknown stranger did it. Hence, ceteris paribus, the defendant is guilty of the rape and murder of the victim.

The warrant of this argument is synthetic. The argument is defeasible - it is not logically impossible that some unknown stranger is responsible for the crime. But if our argument is cogent, the warrant expresses an a priori connection. Hence, the class of defeasible a priori warrants arguably contains some backed by the prime

(C) James B. Freeman. Informal Logic, Vol. 33, No. 2 (2013), pp. 175-194. 


\section{James B. Freeman}

principle of confirmation. Hence, classifying a priori analogical arguments as defeasible a priori, neither deductive nor inductive, is not ad hoc. They are not the only type of argument with a defeasible a priori warrant.

How does our analysis show that Govier's distinguishing $a$ priori from inductive arguments by analogy has implications for assaying a general theory of ground adequacy? Govier has divided these two types of argument by analogy on an epistemic distinction, that between a priori and a posteriori knowledge (or justified belief). Clearly, this is one of the most fundamental and familiar distinctions in epistemology. In assessing whether the premises constitute grounds adequate for the conclusion, this epistemic distinction is fundamental, rather than the recognition that the argument instances the pattern of arguments by analogy. A priori warrants will not be backed by confirming instances and issues in connection with empirical confirmation simply do not apply to assessing arguments with a priori warrants. However, these considerations may be central in evaluating arguments with a posteriori warrants. Hence one step in assessing whether the premises of an argument constitute grounds adequate for accepting the conclusion is identifying the epistemic type to which that argument belongs, provided that the typology "carves nature at it joints." In recognizing at least for the class of arguments by analogy that this epistemic distinction is more fundamental than structural resemblances, we may argue that Govier has been prescient. The distinction cuts across not only arguments by analogy but conductive arguments and indeed arguments in general. It is fundamental to appraising the question of ground adequacy. We hold that another distinction is equally fundamental, that between conclusive and defeasible arguments. The intersection of these two distinctions produces a fourfold typology of arguments or of the considerations and criteria on which their ground adequacy should be evaluated. We are prepared to argue that this fourfold typology is the first consideration

(C) James B. Freeman. Informal Logic, Vol. 33, No. 2 (2013), pp. 175-194. 
in formulating a general theory of connection adequacy. But that argument is the topic of another paper. ${ }^{5}$

\section{References}

Collins, R. (1999). "A scientific argument for the existence of God: The fine-tuning design argument.” In M.J. Murray (Ed.), Reason for the hope within, pp. 47-75. Grand Rapids, MI: Eerdmans.

Copi, I.M. (1986). Introduction to logic, $7^{\text {th }}$ ed. New York: Macmillan Publishing Company.

Freeman, J.B. (2005). Acceptable premises: An epistemic approach to an informal logic problem. Cambridge: Cambridge University Press.

Freeman, J.B. (2011). Argument structure: Representation and theory. Dordrecht: Springer.

Freeman, J.B. (2013 forthcoming). What types of arguments are there? In D. Mohammed and M. Lesinski (Eds.), Virtues of Argumentation: Proceedings of the Tenth OSSA Conference. Windsor, ON: OSSA (CD ROM).

Govier, T. (1999). Euclid's disease and desperate violinists: Do analogies have missing premises? In J. Hoaglund (Ed.), The philosophy of argument, pp. 137-53. Newport News, VA: Vale Press.

Govier, T. (2012). A practical study of argument, $7^{\text {th }}$ ed. Belmont, CA: Cengage Learning.

Harrison, J. (1967). Ethical objectivism. In P. Edwards (Ed. in chief), The encyclopedia of philosophy, Vol. 3, pp. 71-75. New York: Macmillan Publishing Co, Inc. and The Free Press.

Mill, J.S. (1973/1843). A system of logic ratiocinative and inductive: Being a connected view of the principles of evidence and

${ }^{5}$ See our (2013). I want to thank Derek Allen for very useful comments in clarifying an earlier version of this paper.

(c) James B. Freeman. Informal Logic, Vol. 33, No. 2 (2013), pp. 175-194. 
194 James B. Freeman

the methods of scientific investigation, Books I-III. Toronto: University of Toronto Press.

Pojman, L.P. and Rea, M. (2012). Philosophy of religion: An anthology, $6^{\text {th }}$ ed. Belmont, CA: Cengage Learning.

Quine, W.V. (1970). Philosophy of logic. Englewood Cliffs, NJ: Prentice-Hall, Inc.

Rawls, J. (1971). A theory of justice. Cambridge, MA: Harvard University Press.

Ross, W.D. (1930). The right and the good. Oxford: Oxford University Press.

Sober, E. (2004). The design argument. In W.A. Dembski and M. Ruse (Eds.), Debating design: From Darwin to DNA. Cambridge: Cambridge University Press.

(C) James B. Freeman. Informal Logic, Vol. 33, No. 2 (2013), pp. 175-194. 